\title{
Depression And Religiosity in Older Age
}

\author{
M. Pokorski ${ }^{1,2}$ and A. Warzecha ${ }^{2}$ \\ ${ }^{1}$ Medical Research Center, Polish Academy of Sciences, Warsaw, Poland; ${ }^{2}$ Institute of Psychology, Opole University, Opole, Poland
}

\begin{abstract}
We investigated the hypothesis that religious commitment could help counter general affective distress, accompanying depressive symptoms, in older age. A total of 34 older adults, all catholic believers, completed self-reported questionnaires on the presence of depressive symptoms, religiosity, health, worry, and the style of coping with stress. The depressive and nondepressive subgroups were then created. The prevalence of depressive symptoms was $50 \%$, with the substantial predominance of females. Regression analyses indicate that health expectations and worry significantly worsen with increasing intensity of depressive symptoms. The results further show that religious engagement was not different between the depressive and non-depressive subgroups. Religiosity failed to influence the intensity of depressive symptoms or the strategy of coping with stress in either subgroup, although a trend was noted for better health expectations with increasing religious engagement in depressive subjects. We conclude that religiosity is unlikely to significantly ameliorate dysphoric distress accompanying older age.
\end{abstract}

Key words: Age, depression, religiosity, psychosomatic health

\section{INTRODUCTION}

The prevalence of depression in old age is still a controversial issue and epidemiological studies estimate it, depending on the methodology and the population investigated, from about a dozen percentage points [1], through $40 \%$ [2], and to as much as about $70 \%$ [3] in persons over 65 years of age. There is, however, a consistent lay impression that, if depression already is present, advancing old age may worsen its intensity. Depression is a multifactorial condition and encompasses such factors as the overall health status [4], the level of anxiety, or the ability to cope with stressful situations [5-7]. These factors assume distinct characteristics in old age as persons often demonstrate a greater sensitivity or dependence on the external influences. There is a high degree of overlap between these factors, symptoms, and concerns in depressive individuals; the details of which are not fully understood.

A feature of older age often is increased religious activity consisting of one's internal subjective religious beliefs and their external expressions (individual and social behaviors, the practice of religious rites, etc.). A surge in religiosity in old age may be brought about by more mature understanding of the good in one's life or the inescapability of life twilight. The effect of religiosity on psychological health is, however, a contentious issue. Some authors report overall positive effects [8], others negate such an effect [9], while still others relate the effect to a specific disease, e.g., depression, and again the results are contradictory $[10,11]$. Contentiousness of the issue may likely stem from a variety of rather poorly comparable factors, related to age, health, and life conditions of subjects studied.

The objectives of the present study were to investigate the relationships among depression, worry-anxiety, general health, and coping with stress and to assess the effect on them of religious activity in older age. Our working hypothesis was that religious engagement, through, perhaps, trusting in a higher power, may increase personal strength and help cope with the feared psychosomatic stress of old age. Overall, although the findings of this study do point to worsened health outlook and increased worry/anxiety of older age with increasing intensity of depressive symptoms, they provide no support for the notion of an appreciable effect of religiosity on coping with general affective distress accompanying depression in older age.

\section{Study Population And Methodology}

The study was performed in accord with the guidelines of the Declaration of Helsinki for Human Research. All subjects made informed decisions regarding participation in research and they also were ascertained about the anonymity of the results.

The study was carried out in a sample of 34 elderly subjects (F/M-26/8), aged 59-86 years, divided into the depressive and non-depressive subgroups. The subjects were all catholic believers, without overt psychosomatic diseases, not taking any medications that could interfere with completion of the measures, in particular hormonal or psychotropic medications, and constituted a fairly homogenous sample regarding the education (high school -14 subjects and college or university - 20 subjects) and the lower middle-class socioeconomic level.

The methodology consisted of a self-reported group survey. The following psychometric tools were used: the Center for Epidemiologic Studies Depression Scale (CES-D), the Penn State Worry Questionnaire (PSWQ), the General Health Questionnaire (GHQ-12), the Coping Inventory for Stressful Situa- 
tions (CISS), and the Religious Commitment Scale (RCS) by Z. Golan. The CES-D scale, developed by the University of Washington, Seattle, WA, is a 20item scale that regards the frequency of depressive symptoms noted during the week before testing. An aggregate score of $\geq 16$ points indicates the presence of symptoms relating to depression in a tested person [12]. The PSWQ is a 16 item instrument that assesses the trait of worry, corresponding to severe anxiety, and is independent of measures of depression [13, 14]. The GHQ-12 is another screening instrument detecting a spectrum of psychological disorders, mainly having to do with the anxiety-related expectations on general health [15]. In scoring the GHQ, the four statements ranging from "not at all" to "much more than usual" are coded $0,1,2$, and 3 . We used an alternative way of scoring proposed by Goldberg and Williams [16] in which the scale is transformed into a yes/no type by noting 0 and 1 as 0 , and 2 and 3 as 1 . In the latter two scales, the higher is the score the more worry and worse health expectations.

The CISS scale is a measure of Emotion-, Task-, and Avoidance-oriented coping which has been validated in both depressed and non-depressed subjects $[17,18]$. The RCS is a scale construed by a Polish catholic priest, Z. Golan. The scale consists of 28 items, each being a 7 -point scoring continuum. The questionnaire is evenly divided into two statement parts which separately assess internal and external religious activities. Either part, in turn, is divided into two subscales named Prayer and Religiosity, concerning internal religious involvement, and People and Church, concerning external involvement. The scale assesses the degree of one's religiosity understood as religious engagement [19] which in a way relates to a concept of committed religion earlier put forward by Allen and Spilka [20]. The concept puts emphasis on the psychological attitude, taking into account the cognitive, emotional, and behavioral aspects toward religious activity. This activity realizes tasks put forward by religion in both internal - the Roman Catholic perseverance and care about the sustainment of prayer and religiosity and external - the fulfillment of goals set by a religious communion and adherence to moral principles domains. Religious engagement may thus be taken as a reflection of religious maturity.

All the psychometric tools used are reliable and sensitive screening instruments in the respective domains of a psychological testing process. They are widely used, validated in large samples of subjects across genders in many a study, and have high internal consistency and good test-retest reliability.

Raw score data were tallied in each questionnaire for each individual and the mean tally \pm SE was calculated for the depressive and non-depressive subgroups. Differences between the mean results of the two subgroups were evaluated with an unpaired t-test. Correlations between individual parameters were evaluated using linear regression according to the equation: $\mathrm{y}=$ $\mathrm{ax}+\mathrm{b}$. Categorical variables were compared with $2 \times 2$ contingency table with Yates's correction. $\mathrm{P}<0.05$ was taken as indicative of statistical relevance in the whole survey. Statistical evaluation was performed with an SPSS-12 commercial package.

\section{RESULTS}

We found the intensity of depressive symptoms, above the cut-off mark of 16 points, indicative of probable psychological depressive distress, in $50 \%$ of the subjects studied (17 out of the 34 subjects). The prevalence of depressive symptoms was distinctly greater in the aged females $(62 \%)$ as only one male was found in the depressive subgroup. College-university/high school education of subjects was distributed as follows: in the depressive group 7/10 and in the non-depressive group 13/4. The null hypothesis set for the chi-square analysis that there was no difference between the level of education and the appearance of depressive symptoms was disapproved $\left(\chi^{2}=5.95\right.$; $\mathrm{P}<0.02)$. It is, therefore, quite conceivable that depressive symptoms were prevalent among lower educated subjects.

The mean score of depressive symptoms amounted to $27.9 \pm 2.5$ points in the group marked as depressive vs. $8.2 \pm 1.1$ points in the non-depressive subgroup $(\mathrm{P}<0.001)$. The intensity of depressive symptoms was thus moderate taking into account the maximum 60 points achievable in the scale. Interestingly, depressive symptoms remained virtually unchanged when related to the advancing senior age in the subjects whose score was either below or above the cut-off mark. The linear regression lines describing the intensity of symptoms on age remained nearly flat in both subgroups; with a greater scatter of data present in the depressive subgroup (Fig. 1).

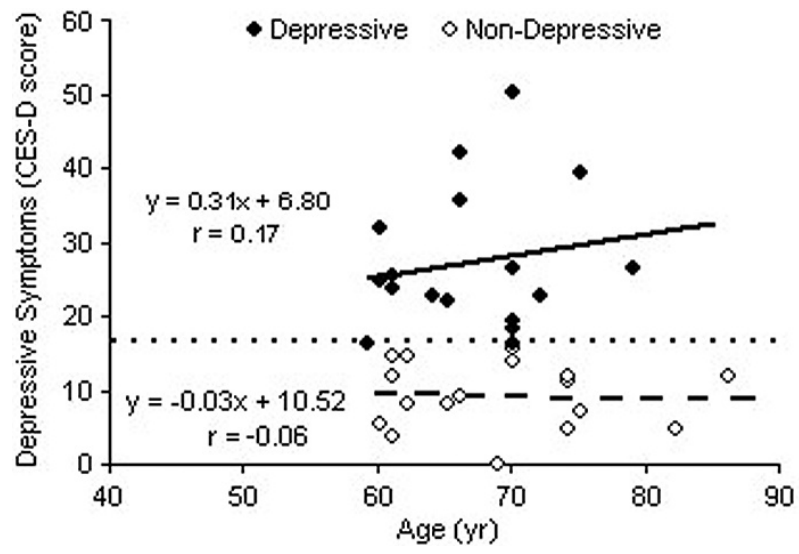

Fig. 1. Intensity of depressive symptoms below and above the 16 point cut-off mark (dotted line) in the CES-D scale in subjects of advancing senior age. Lines are the corresponding linear regression lines.

The mean scores for health expectations and worry in both subgroups of subjects are shown in Table 1. On average, depressive subjects demonstrated enhanced feelings of ill general health and worry. In both subgroups, however, these feelings depended on the intensity of depressive symptoms. Therefore, data for the whole population were pooled to study the mutual relationships. Both health expectations and worry significantly worsened with increasing symptom intensity, as assessed from the linear regression analysis in the scatter diagrams pooled from data of both 
Table 1. Scoring in religious commitment scale (RCS) and in the feelings of general health (GHQ-12) and worry (PSWQ) in the depressive and non-depressive subgroups stratified on the basis of frequency and intensity of depressive symptoms (CES-D).

\begin{tabular}{lccc}
\hline Depression & RCS & GHQ-12 & PSWQ \\
\hline Yes $(\mathrm{n}=17)$ & $105.2 \pm 5.8$ & $3.7 \pm 0.7$ & $50.2 \pm 2.0$ \\
No $(\mathrm{n}=17)$ & $105.4 \pm 9.9$ & $0.6 \pm 0.2^{*}$ & $39.3 \pm 2.6^{* *}$ \\
Max. possible score & 196 & 12 & 80 \\
\hline
\end{tabular}

Data are means $\pm \mathrm{SE}$ of raw points. $* \mathrm{P}<0.0001$ and $* * \mathrm{P}<0.002$ for the differences between the depressed and non-depressed groups.

subgroups studied; $\mathrm{P}<0.001$ for the relationships between the GHQ-12 and CES-D scores and the PSWQ and CES-D scores (Fig. 2 and Fig. 3, respectively). It follows that there was a positive association between the worsening feeling of general health and that of worry ( $\mathrm{r}=0.52, \mathrm{P}<0.01$; graphical data not shown).

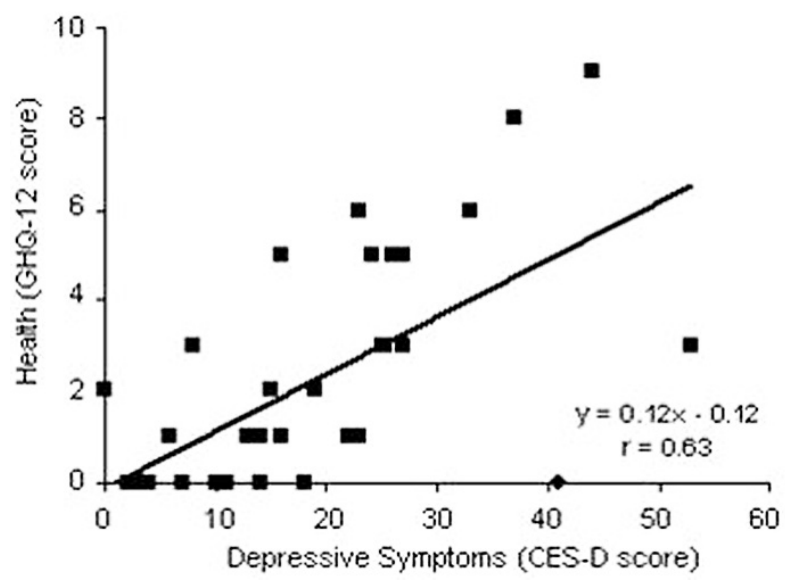

Fig. 2. Association between the general health outlook and the intensity of depressive symptoms. Line is a linear regression line.

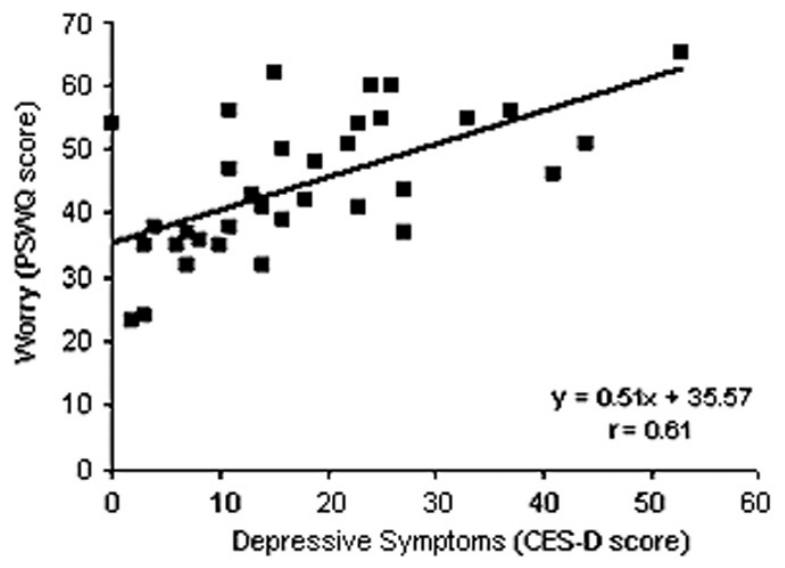

Fig. 3. Association between the feeling of worry and the intensity of depressive symptoms. Line is the linear regression line.
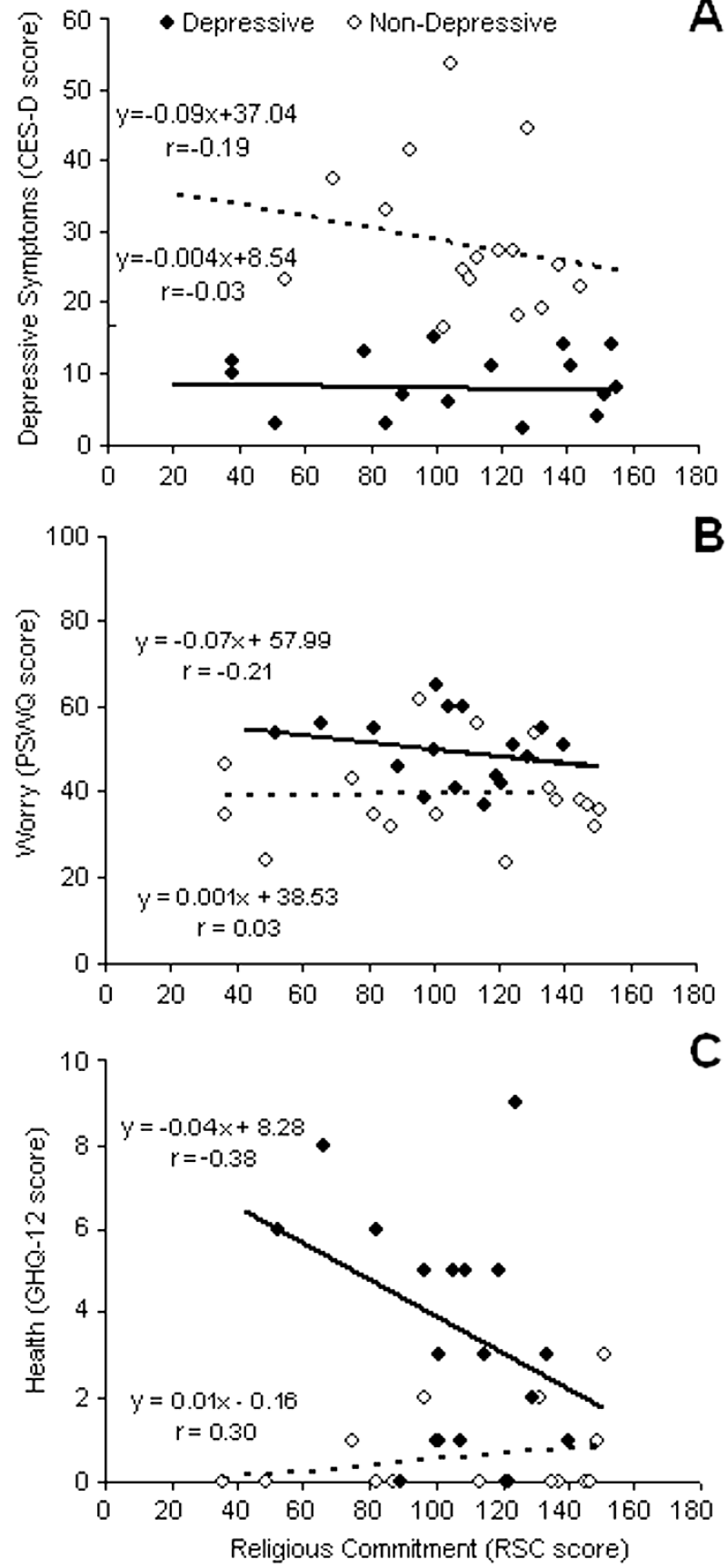

Fig. 4. Relationship between religious engagement and intensity of depressive symptoms (Panel A), worry (Panel B), and general health expectations (Panel C) in depressive and nondepressive subjects. Lines are linear regression lines drawn through the respective sets of symbols. None of the correlation coefficients were significant at $\mathrm{P}<0.05$.

The survey placed religiosity at a moderate level in the population studied, with the RCS scoring, on average, in a range of $50 \%$ of achievable points. The mean scores describing religious activity and commitment did not appreciably differ between the depressive and non-depressive subgroups (Table 1). When the population studied was analyzed as a whole, irrespective of the intensity of depressive symptoms, we could not support the notion that enhanced religious engagement would associate with better health expectations 
Table 2. Distribution of strategies of coping with stress in the depressive and non-depressive subgroups of subjects.

\begin{tabular}{lccc}
\hline Depression & Emotion & Avoidance & Task \\
\hline Yes $(\mathrm{n}=17)$ & 5 & 4 & 8 \\
No $(\mathrm{n}=17)$ & 1 & 2 & 14 \\
\hline
\end{tabular}

or less worrying, as these relationships were flat and insignificant (graphical data not shown). When the subjects were classified by the intensity of depressive symptoms, we likewise failed to find any meaningful effects of enhanced religious engagement on the intensity of depressive symptoms (Fig. 4A), the feeling of worry (Fig.4B), or the perception of health status (Fig. 4C) in either subgroup. All these associations were statistically insignificant, although in the last case there was an apparent trend for better health expectations in the depressive subgroup of subjects with increasing score of religious commitment $(0.10>\mathrm{P}>$ 0.05).

We, however, found that the subgroup of depressive subjects demonstrated a predominance of lessadaptive coping strategies (i.e., Emotion- and Avoidance-oriented), whereas the reverse was found in the non-depressive subjects, where the more adaptive coping strategy (i.e., Task-orientated) predominated. Details of the distribution of coping with stress strategies in both subgroups are shown in Table 2. Here we erected the null hypothesis that there was no difference between the distribution of subjects by the style of coping with stress in the depressive and non-depressive subgroups. The results failed to clearly disprove the hypothesis, likely due to sparsity of cases in each class of coping style, although a trend for Taskoriented coping appeared in the non-depressed $\left(\chi^{2}=\right.$ 4.97; 0.10 $>\mathrm{P}>0.05)$.

\section{DISCUSSION}

In the present study we sought to determine the influence of religiosity on the interrelationships among depression, anxiety-worry, general health, and the strategy of coping with stress in older age. Our working hypothesis was that enhanced religious engagement could help grapple with the psychosomatic stress of old age, which would show up in a more adaptive way of counteracting stressful situations, better health outlook, and less dysphoric/worry type of attitudes in senior subjects. We based this presumption on the fairly consistent impression that senior persons often turn to religious and spiritual resources as an obvious result of anxiety related to worsening somatic health, increased dependency on caregivers, and possible decline in mood due to the feeling of passing time and nearing the end-life. We deemed, therefore, worthwhile to explore the potential of religiosity to affect psychological health in the elderly. Furthermore, we reasoned that the affirmative effects of religiosity could better come to sight in subjects who demonstrate clear depressive symptoms. To this end, we first sorted out a group of subjects displaying an increased intensity of depressive symptoms, indicating the possi- bility of depression-like state, on the basis of CES-D screening test. Overall, although the findings of this study do point to worsened health outlook and increased anxiety/worry of old age with increasing intensity of depressive symptoms, they provide no support for the notion of appreciably better coping with them when religiosity is enhanced.

There are reports showing that increased religiosity, in particular of the intrinsic sort, i.e., one's commitment to religious beliefs, decreases depression scores in elderly in-patients with depression [10]. Spiritual wellbeing and prayer, but not so much the frequency of attendance at religious services, is a predictor of psychological wellbeing in older adults [21]. In another study, however, performed in heterogeneous medical population sample, attendance at religious services shows some positive effects on physical health [22]. Frequency of attendance at religious services is inversely associated with herpes simplex type 2 and hepatitis $C$ virus infections [23] and those who attend services more often than once a week have an appreciable decrease in systolic blood pressure of more than $3 \mathrm{mmHg}$ [8]. The aforementioned studies concern elderly patients with a definite diagnosis of major depression, which necessitated hospitalization, patients severely handicapped due to disease, or young adults in their twenties or somewhat older. Similar studies performed in the general senescent public at large are scarce. Some studies point to the positive effect of religious service attendance and strength of belief on all-cause mortality, but not regarding specific diseases, like coronary heart disease; a notable example of advanced age morbidity [24]. Those studies also devote attention mostly to religious and spiritual services and resources, but do not take stand on the plausibly differential influence of various religious creeds. The issue of religiosity also is contentious even concerning young people, as a number of other studies apparently contradict the existence of any positive effects of enhanced religiosity on psychosomatic health aspects [9]. Even if religiosity makes the perception of health better, it apparently has the least of an effect on depressive symptomatology [11]. Religiosity is a complex socio-cultural phenomenon whose influence on the psychosomatic condition remains controversial. Nevertheless, depression, viral infections, and hypertension are all often accompaniments of the aging process, which raises an interest concerning a plausible, innately beneficial character of religiosity in old age.

In the present study we found a $50 \%$ prevalence of depressive symptoms in the senior population studied. The prevalence of depressive symptoms in older age is variably reported at about $20,35,40$, or even $70 \%$ [2, 3, 25-27]. Despite these differences, there seems now to be a consistent impression that this prevalence is less in the elderly than in the young [28]. It seems that older females have a greater predilection for the presence of depressive symptoms than males [2]; also a finding of the present study in which there was a $62 \%$ prevalence of these symptoms in females alone. At the same time, the depressive symptoms were not increasing with advancing senior age, which is in accord with some of the previous findings [2]. The large spread of percentage data concerning the prevalence of depres- 
sion, outlined above, has likely to do with the different psychometric methodologies used to assess depressive symptomatology, different populations studied, possibly different symptoms and their course in the elderly, and a range of comorbidities, more often than not accompanying depression in the elderly. Depression often overlaps, to an extent, with anxiety states. Properties of anxiety and depression include the convergent feelings of worry or ill health, and worsened expectations for the future general health, all belonging to general affective distress $[29,30]$. In the present study we provide confirmatory data to this end, showing the associations between worsening health outlook or increased worrying and the intensity of depressive symptoms (Figs. 2 and 3).

This study has limitations, often inherent in group surveys, such as the choice of psychometric tools used or the assiduity of responders in marking answers in questionnaires, both able to introduce a bias and having a potential, albeit inadvertent, bearing on the results obtained. The subjects who were enrolled into the study showed, on average, a moderate level of religious commitment, so that the results may not be applicable to the more dedicated persons of a religious group. The study population also was of a relatively small number, and it might have not reflected the general public.

With the above outlined limitations in mind, we believe we have shown that the presence of depressive symptoms in older age worsens health expectations of an individual and enhances his worry and anxiety about everyday functioning. These undesirable feelings are mutually self-driving and might affect clinical depression, if present. The level of religious commitment in older age has no substantial influence on the intensity of depressive symptoms, the strategy of coping with stress, or on the perception of general health status. The lack of a positive effect of religiosity is rather an unexpected finding that may have to do with the catholic theological emphasis on sinfulness concerning offending moral or ethical principles, which can bear on one's mood. We opine, therefore, that comparative studies on the effects on psychosomatic health of religiosity should take into consideration the kind of religious denomination being under study.

Acknowledgments: This work was supported by the statutory budget of the Institute of Psychology of Opole University in Opole, Poland.

Conflicts of interest: The authors declare no conflicts of interest in relation to this article.

\section{REFERENCES}

1. Wittchen HU, Knauper B, Kessler RC. Lifetime risk of depression. Br J Psychiatry Suppl. 1994; 26: 16-22.

2. Pokorski M, Siwiec P. Memory, depression, and progressing old age in women. J Physiol Pharmacol. 2006; 57 Suppl 4: 297-304.

3. Marquez Cardoso E, Soriano Soto S, Garcia Hernandez A, Falcon Garcia MP. Depression in the older adult, frequency and associated risk factors. Aten Primaria. 2005; 36: 345-6.

4. Cully JA, Gfeller JD, Heise RA, Ross MJ, Teal CR, Kunik ME. Geriatric depression, medical diagnosis, and functional recovery during acute rehabilitation. Arch Phys Med Rehabil. 2005; 86: 2256-60.
5. Chiam PC. Depression of old age. Singapore Med J. 1994; 35: 404-6.

6. Fombonne E. Increased rates of depression: Update of epidemiological findings and analytical problems. Acta Psychiatr Scand. 1994; 90: 145-56.

7. Lépine JP, Bouchez S. Epidemiology of depression in the elderly. Int Clin Psychopharmacol. 1998; 13 Suppl 5: S712.

8. Gillum RF, Ingram DD. Frequency of attendance at religious services, hypertension, and blood pressure: the Third National Health and Nutrition Examination Survey. Psychosom Med 2006; 68(3): 382-5.

9. Schmied LA, Jost KJ. Church attendance, religiosity, and health. Psychol Rep. 1994; 74: 145-6.

10. Payman V, Ryburn B. Religiousness and recovery from inpatient geriatric depression: Findings from the PEJAMA Study. Aust N Z J Psychiatry. 2010; 44: 560-7.

11. Pikó B, Kovács E. Is religiosity a protective factor? Social epidemiologic study of adolescent psychological. Heath Orv Hetil. 2009; 150:1903-8 (Article in Hungarian).

12. Weissman MM, Sholomskas D, Pottenger M, Prusoff BA, Locke BZ. Assessing depressive symptoms in five psychiatric populations: A validation study. Am J Epidemiol. 1977; 106: 203-14.

13. Meyer TJ, Miller ML, Metzger RL, Borkovec TD. Development and validation of the Penn State Worry Questionnaire. Behav Res Ther. 1990; 28: 487-95.

14. Shearer S, Gordon L. The patient with excessive worry. Am Fam Physician. 2006; 73: 1049-57.

15. Goldberg DP, Hillier VF. A scaled version of the General Health Questionnaire. Psychol Med. 1979; 9: 139-45.

16. Goldberg DP, Williams P. A user's guide to the General Health Questionnaire. NFER/Nelson, Windsor, 1988.

17. Endler NS, Parker JDA. Coping Inventory for Stressful Situations (CISS): Manual (Revised Edition). Toronto, Multi-Health Systems, 1999.

18. McWilliams LA, Cox BJ, Enns MW. Use of the Coping Inventory for Stressful Situations in a clinically depressed sample: Factor structure, personality correlates, and prediction of distress. J Clin Psychol. 2003; 59: 423-37.

19. Golan Z. 1992. Personality and religious engagement. ATK Warsaw (in Polish).

20. Allen RO, Spilka B. Committed and consensual religion: A specification of religious prejudice relationships. J Sci Study Relig. 1978; 6: 191-202.

21. Lawler-Row KA, Elliott J. The role of religious activity and spirituality in the health and well-being of older adults. J Health Psychol. 2009; 14(1): 43-52.

22. Campbell JD, Yoon DP, Johnstone B. Determining relationships between physical health and spiritual experience, religious practices, and congressional support in a heterogeneous medical sample. J Relig Health. 2010; 49: 3-17.

23. Gillum RF, Holt CL. Religious involvement and seroprevalence of six infectious diseases in US adults. South Med J. 2010; 103(5): 403-8.

24. Schnall E, Wassertheil-Smoller S, Swencionis C, Zemon V, Tinker L, O'Sullivan MJ, Van Horn L, Goodwin M. The relationship between religion and cardiovascular outcomes and all-cause mortality in the Women's Health Initiative Observational Study. Psychol Health. 2010; 25(2): 249-63.

25. Jones M. Using screening tools to identify the risk or presence of depression in older people. Nurs Times. 2009; 105(49-50): 24-7.

26. Urbina Torija JR, Flores Mayor JM, García Salazar MP, Torres Buisán L, Torrubias Fernández RM. Depressive symptoms in the elderly. Prevalence and associated factors. Gac Sanit. 2007; 21(1): 37-42 (Article in Spanish).

27. Waugh A. Depression and older people. Nurs Older People 2006; 18(8): 27-30. 
28. Pokorski M, Siwiec P. Depression and memory: A comparative study of young and old women. J Physiol Pharmacol. 2008; 59 Suppl 6: 573-8.

29. Clark LA, Watson D. Tripartite model of anxiety and depression: Psychometric evidence and taxonomic implications. J Abnorm Psychol. 1991; 100(3): 316-36.

30. Manthorpe J, Iliffe S. Anxiety and depression. Nurs Older People. 2006; 18 (1): 25-9.
Received: December 21, 2010 / Accepted: April 30, 2011

Address for correspondence:

M. Pokorski

Medical Research Center

Polish Academy of Sciences

5, Pawinskiego St.

02-106 Warsaw

Poland

Phone/Fax: +48 226086622

E-mail: m_pokorski@hotmail.com 